\title{
MSH2 Nuclear Expression Intact
}

National Cancer Institute

\section{Source}

National Cancer Institute. MSH2 Nuclear Expression Intact. NCI Thesaurus. Code

C160416.

An indication that expression of $\mathrm{MSH} 2$ was detected in the nuclei of cells in a sample. 